\title{
COVID-19 and the Digital Ecosystem: Using a Mobile App to Connect a Rural Community
}

\author{
Vusumuzi Maphosa ${ }^{1 *}$
}

\author{
${ }^{1}$ Lupane State University, ZIMBABWE \\ *Corresponding Author: vmaphosa@lsu.ac.zw
}

Citation: Maphosa, V. (2021). COVID-19 and the Digital Ecosystem: Using a Mobile App to Connect a Rural Community. Aquademia, 5(1), ep21002. https://doi.org/10.21601/aquademia/9580

\section{ARTICLE INFO}

Received: 20 Aug. 2020

Accepted: 23 Nov. 2020

\begin{abstract}
The outbreak of the novel coronavirus disease in 2019 disrupted every aspect of human life, threatening the world's public health system. Most countries accelerated their transition to digital technologies that support healthcare, social activities, learning, and shopping to minimise these disruptions. As COVID-19 propels nations towards the digital economy, epitomising the data age, the digital divide will be more pronounced even within the same country. The transition to the digital space has exposed Africa's infrastructural deficiencies. Zimbabwe's rural communities have limited access to information related to COVID-19 due to the unavailability of radio and television reception. In light of limited access to radio, television, and newspaper by rural communities, the study sought to develop a mobile app that can enhance access to information related to COVID19. The Information System Development Methodology and agile software design principles guided the development of the app. The evaluation results show positive feedback regarding the usefulness and utility of the app. The findings indicate that the participants found the app very easy to remember, easy to learn, and perceived that it satisfied their information access needs. The results can be useful in improving the deployment of digital health solutions targeting rural and remote communities.
\end{abstract}

Keywords: digital divide, mobile apps, COVID-19, agile software development, information system development methodology, evaluation

\section{INTRODUCTION}

The outbreak of the severe acute respiratory syndrome coronavirus 2 (SARS-CoV-2), the virus that causes COVID-19, has become an international public health emergency after spreading across the globe (Wang, Horby, Hayden, \& Gao, 2020). Millions of lives across the world are at risk of infection and death. On the $11^{\text {th }}$ of March 2020, the World Health Organization declared the coronavirus COVID-19 a pandemic. This forced many countries to develop measures restricting its transmission, such as curfews, social distancing, and encouraging the population to stay at home (Sezgin, 2020). By the first week of November 2020, COVID-19 had affected 218 countries, with more than 45 million confirmed cases, 36 million recoveries, and 1.1 million reported deaths globally (Worldometers, 2020). The restrictions have affected business, industry, education, and consequently altered the daily course of life for many people worldwide. The impact of COVID-19 has made the world turn to digital technologies for work, shopping, learning, and other social activities (Sezgin, 2020). Reports reveal that over 4 billion people used the internet in 2019, with Africa accounting for only 18\% (Whitelaw, Mamas,
Topol, \& Van Spall, 2020). Africa should start using ICTs to drive its economic and social systems during COVID-19 to increase information flow, trade and enhance entrepreneurial activities. However, lack of ICT infrastructure undermines these efforts (Africaportal, 2020).

The COVID-19 lockdown has forced the world to shift from traditional in-person services to internet and remote-based services. This new mode of operation will isolate many communities in Africa, as they fail to access telemedicine, learning, and information to reduce their exposure to the virus (IPS, 2020). Many countries in the developed world have accelerated their transition towards the digital economy resulting in the emergence of many digital solutions meant to sustain individuals, businesses, and government during the lockdown period (Neweurope, 2020). The virus has affected the socio-economic environment, forcing entities to use digital technologies to drive their operations' reconfigurations and all adaptations in this new order (Wijesooriya, Mishra, Brand, \& Rubin, 2020). The pandemic has forced the world to take an extraordinary digital leap in its everyday life and practices, including the education sector.

Scholars have attested that ICTs have the potential to improve access to information that can stir socio-economic 
growth and reduce poverty in Africa (Aker \& Mbiti, 2010; Shambare, 2014). Structural barriers, such as lack of access to energy sources, poor roads, and poor governance, have negatively impacted efforts to bridge the digital divide (Meshur, 2012). The mobile phone is one technological device that has transformed Africa's socio-economic development landscape through improved communication, access to information and financial services, education, and health information (Damasen \& Uhomoibhi, 2014). Improved investment and growth of Africa's mobile telecommunications infrastructure offer exciting and new opportunities, such as improved access to digital services, including health care (Tugnayat, Regulwar, \& Tugnayat, 2012). Mobile phone penetration in Zimbabwe rose to $102.7 \%$, while internet penetration rate rose to $50.8 \%$ by 2017 (POTRAZ, 2017). The mobile phone has bridged Zimbabwe's digital divide with about 90\% ownership in rural areas when compared to the computer, which has three per cent ownership in rural areas and 24\% for urban dwellers (Zimstats, 2014).

One way of controlling the spread of COVID-19 is by providing access to appropriate and up-to-date information about the spread of the pandemic and how communities could protect themselves. In most remote communities, information sources are scarce, scattered and limited, affecting information dissemination, response efforts, and preparedness. Radio and television broadcasts have been considered the most effective media for disseminating information to rural and remote communities. Matsa and Simphiwe (2014) contended that most rural districts of Zimbabwe do not have access to information that affects their daily lives, such as disease outbreaks, agricultural information, and news due to the absence of television and radio reception. Other scholars noted that communities in Nigeria who lacked access to official information channels were exposed to wrong information, which worsened Ebola management (Otu, Ebenso, Okuzu, \& Osifo-Dawodu, 2016). This paper aims to develop and evaluate a COVID-19 app for enhancing access to information by rural communities in Zimbabwe. Effective use of technology should respond to local level problems by developing solutions cognisant of local-level contexts. The app evaluation measures the usefulness, design, learnability, memorability, and satisfaction of the user.

\section{LITERATURE REVIEW}

Musingafi et al. (2011) concluded that ICTs could increase socio-economic development opportunities in rural areas through improved access to information related to markets, health, and education. ICT solutions developed for rural communities should provide context-specific information that impacts the community's day to day life (Aker \& Mbiti, 2010; Beuermann, McKelvey \& Vakis, 2012). Rashid and Elder (2009) determined that the mobile phone had become a vital tool to fight the digital divide in Africa by providing low-cost access to information that could help reduce poverty and improve livelihoods. Researchers have projected that mobile internet in Africa would increase by 20 -fold in the next five years; therefore, researchers and technologists should develop local- level solutions that take advantage of this ubiquity (Aker \& Mbiti, 2010; Allgaier \& Svalastog, 2015).

The Zimbabwean population is mostly rural (67\%), with $33 \%$ of the population residing in urban areas (Zimstats, 2014). Most rural communities in Zimbabwe can only access socioeconomic information and information related to health, education, and news through radio and television. Lack of access to radio and television reception by rural communities is a gross human rights abuse and a violation of their fundamental rights and freedoms (News Day, 2016). Other information sources for rural communities are newspapers, with a 33\% circulation rate in rural areas (Tech Target, 2013). Fewer people are likely to access newspapers as movement is restricted because of curfews and other restrictions imposed during COVID-19. Therefore, new strategies should be employed to improve access to information by rural communities. Besides Zimbabwe's high cost of data, rural populations can effectively utilise mobile apps as rural mobile phone penetration rate is over $90 \%$, while literacy levels are over 90\% (Lancaster, 2016).

Humanity will depend more on the internet and associated technologies to sustain livelihoods and still maintain COVID19 restrictions such as social distance (Africaportal, 2020). The new order brought by COVID-19 provides an opportunity to pursue alternative plans that ensure that the whole population can access critical information regarding the pandemic. Effective management of COVID-19 requires strategies that will take care of the needs of rural communities, to inform and educate them on how they could protect themselves from the pandemic. These communities should access COVID-19 information such as the statistics, curfews, and other measures meant to restrict the virus's transmission. Radio and television coverage in most rural communities in Zimbabwe is low, and the country has not yet established community-based radio stations to broadcast local and community-specific information (Maphosa, 2020).

As COVID-19 disrupts human life, there is a growing fear that some populations in the developing world may be left behind, which may further widen the digital divide post the pandemic (Neweurope, 2020). The digital divide in Africa is entrenched in its complex social and ethnic discrimination, resulting in structural inequalities (Sezgin, 2020). The new order under the COVID-19 will further widen the digital divide between the Global North and the Global South, urban and rural, and create social groups within the same country (Neweurope, 2020). Pre-existing inequalities related to education, income, wealth, and access to electricity manifest through a lack of access to digital technology in most developing countries (IPS, 2020). Many people in Africa do not have the resources to access appropriate technology such as laptops and high-speed broadband internet, limiting their ability to work from home (Africaportal, 2020). Iivari et al. (2020) described the different digital divides that exist as those with no access to digital technology and those with access but do not have the skills to traverse through the digital world. The digital divide will be more pronounced in Africa as the world migrates every aspect of our daily life to online platforms to reduce physical contact.

While most of Africa is lagging, many countries worldwide have developed mobile apps that offer citizens information on 
the pandemic, track infections, and diagnostics. Poor broadband network infrastructure across Africa limits connectivity, inhibiting communities from accessing essential online services, disadvantaging workers who may want to telecommute, and students who could attend online classes (Neweurope, 2020). Iivari et al. (2020) noted that the sudden shift to digital technologies exposed parents and children who have to apply some digital skills in supporting remote learning to ensure that the lockdown did not significantly impact their children's education. There are concerns about the digital divide's impact on Africa's education sector and livelihoods as the digital divide drives some communities to the brink of socio-economic collapse (TRTWorld, 2020). While over $85 \%$ of institutions elsewhere migrated into online learning, only $29 \%$ of learning institutions in Africa have moved to the online environment (Marinoni, van't Land, \& Jensen, 2020). Zimbabwe is also lagging; for example, the government has adopted radio broadcasts to support remote-based learning for primary and secondary school learners (MoPSE, 2020), ahead of online technologies, which may be more appealing to today's learners. The quality of education in Africa will deteriorate as many learners fail to access appropriate technology for remote learning, resulting in many dropping out of school (TRTWorld, 2020).

Digital technologies have proved to be the new order during the current COVID-19 lockdown, offering opportunities that limit significant disruptions to our lives. To ensure that rural people's lives are not interrupted by the current restrictions, technologists should develop new digital solutions that enable access to information, teleworking, and constant updates on the pandemic. Many countries have invested in their digital infrastructure and created new digital solutions to support their citizens and other measures such as quarantines, closure of borders, and suspension of interstate, intrastate, or city travels (Neweurope, 2020).

Mobile apps are software applications running on handheld devices. Mobile apps are broadening prospects for healthcare management in developing countries, resulting in a surge in their use (Hussain et al., 2017). Mobile phone health apps are vital in providing affordable and quality health care, which can enhance the safety of the patients (Chatzipavlou, Christoforidou, \& Vlachopoulou, 2016). Tran and Houston (2012) noted that mobile phones positively impacted healthcare as patients could access health information apps and use the phone's reminders and alarms to improve drug adherence. Researchers estimate that over 1.7 billion patients will access health information and services through apps, and this will improve health care (Nguyen \& Poo, 2016). Governments and network operators partnered in developing mobile apps to educate and support behavioural change during the Ebola outbreak across Guinea, Liberia, and Sierra Leone (Out et al., 2016). Ranscombe (2020) found out that Liberians only began to understand its effect on their lives after accessing non-technical and specific information about the disease during the Ebola crisis. Allgaier and Svalastog (2015) reported that some people had died and others hospitalised by accessing inappropriate information such as eating raw onion and drinking coffee, among others, to prevent Ebola infections. Consequently, during the COVID-19 pandemic, it is vital to provide rural communities access to reliable information regarding the disease, transmission, and prevention to save lives.

Several applications have been developed to combat the spread of the pandemic and help prevent infections by providing information that empowers the population to deal with the disease. Most countries in the developed world have built apps to track infections through contact tracing. COVID19 tracking apps can detect and report symptoms and also use Bluetooth signals to get unique IDs of phones that have come within the phone's radius. When the phone owner develops COVID symptoms, the app can help the medical team identify all the other users who were within two metres of the user (Venkataraman, 2020).

Tracking apps can track individuals for testing and treatment if they test positive (Venkataraman, 2020; Neweurope, 2020). The RAKNING C-19 is the Icelandic national official app which offers contact tracing by using the individual's GPS location to trace their travels and identify individuals they may have come into contact with (Mhealthhub, 2020). This information can be passed on to the health department to trace individuals who may need quarantining. Cyprus's CoyTracer app tracks infected patients to protect frontline workers by using safe paths for quarantine (mhealthhub, 2020). A contact tracing app developed in Singapore stores mobile phone records of individuals that came into proximity with the user for possible COVID-19 transmission for a 21-day window to help trace individuals (Whitelaw et al., 2020). The Open Coronavirus app facilitates monitoring, diagnosing, and containing the infections to help the health system cop with the infections (mhealth-hub, 2020). Several COVID-19 screening apps were developed in South Africa, such as the Keep.Out.COVID app which allows users to complete a symptoms questionnaire and instantly get feedback on whether they are at risk (EWN, 2020). Keep.out.COVID app will reduce healthcare burden by allowing companies to use infra-red thermometers on-site to capture employees' temperatures and noting any variations.

\section{METHODOLOGY}

Pragmatism is a paradigm generally associated with mixedmethods research, which asserts that reality can be observed through an angle that leans towards solving practical problems affecting communities (Martina, 2010). The study followed the Information System Development Methodology (ISDM) developed by Wayi and Huisman (2010) to guide the COVID19 information app development. Following the ISDM improves the development and deployment of rural-based information systems. The ISDM framework considers the community's socio-economic environment and the roles of the users in the system. Agile software design principles and the ISDM fit well as both involve establishing the problem and gathering the users' requirements. After gathering the user requirements, the prototype is developed through the build and evaluate sessions involving the user. The development followed the distinct stages of the ISDM guided by agile methodologies from conception, design, evaluation, and delivery of a solution to the users. 
Table 1. App evaluation

\begin{tabular}{|c|c|c|c|c|}
\hline Survey item & A & $\mathrm{N}$ & Mean & SD \\
\hline Usefulness & 0.72 & & 4.41 & \\
\hline The app improved my access to health information. & & 20 & 4.70 & 0.77 \\
\hline I could access the content when the network was poor or when I did not have credit & & 20 & 4.46 & 0.52 \\
\hline I used the app with no frustration & & 20 & 4.35 & 0.65 \\
\hline I would recommend the app to others & & 20 & 4.11 & 0.84 \\
\hline Learnability & 0.79 & & 4.56 & \\
\hline $\begin{array}{c}\text { I found it easy to learn how to use the app } \\
\end{array}$ & & 20 & 4.31 & 0.48 \\
\hline I found it easy to understand how the app works. & & 20 & 4.62 & 0.51 \\
\hline The terminology used is understandable & & 20 & 4.71 & 0.72 \\
\hline I could use the app without seeking assistance & & 20 & 4.59 & 0.52 \\
\hline Satisfaction & 0.82 & & 4.35 & \\
\hline I am content with the information provided by the app & & 20 & 4.19 & 0.76 \\
\hline I found the content relevant to my needs & & 20 & 4.62 & 0.53 \\
\hline I found the app user friendly & & 20 & 4.24 & 0.82 \\
\hline Design & 0.71 & & 4.39 & \\
\hline The design of the graphics and menus is satisfactory & & 20 & 4.08 & 0.86 \\
\hline The navigation was consistent when moving between screens. & & 20 & 4.69 & 0.48 \\
\hline Memorability & 0.65 & & 4.51 & \\
\hline I could remember how to use the app even after stopping using it & & 20 & 4.43 & 0.75 \\
\hline The app could remember the last page I last opened & & 20 & 4.58 & 0.56 \\
\hline
\end{tabular}

The ISDM supports a user-centred approach that allows users to be involved in the development of the app to ensure that the app meets their needs. The first stage of the ISDM and agile development process is problem specification. This app intends to solve the lack of access to reliable information related to the COVID-19 pandemic due to radio, television, and print media unavailability. The second stage involved examining the feasibility of the proposed solution by comparing it to existing apps that were discussed in the literature review section. Paper-based sketches of the prototype were developed and presented to the users to gather their input and feedback before development. The users contributed to the structuring of the content and the functional requirements of a mobile app. The development stage involved turning the theoretical objectives into a working model by building a working solution. The user inputs were incorporated into the design considerations, such as icon arrangement and implementation of a low bandwidth app due to their socio-economic environment. The user input allowed for swift modification and improvement of the app. The Android Mobile Phone Operating System runs the app's front end while the back end uses Apache. The following stage involves evaluating the app's functionality to determine how it can solve the stated problem. The participants evaluated the app during the two months trial period.

\section{Participants}

The potential users of the app who participated in the study were randomly drawn from the rural community. The majority of the participants were female 13 (65\%), while males were 7 (35\%). Half of the participants were in the 25-35 years age group; $20 \%$ of the participants were in the age group 18-24 years, while $30 \%$ were over 35 years. All the participants owned an Android-based smartphone.

\section{Instrument}

A 5-point usability criterion from the Nielsen Norman Group (2016) was used to develop the questionnaire that guided the app evaluation. The criteria include learnability, memorability, satisfaction, design, and usefulness. As shown in Table 1, four questions focused on usefulness, another four on learnability, three on satisfaction, while two centred on design, and the last two on memorability. The first part of the questionnaire covers the participant's demographics. The reminder evaluates the app's usability using a 5-point Likert scale of which " 1 " indicates a Strongly Disagree and "5" indicates a Strongly Agree. A quantitative data analysis method measured the mean, standard deviation and validated the responses' internal consistency using Cronbach's alpha $(\alpha)$.

\section{OVERVIEW OF THE APP}

One obstacle in fighting the coronavirus is the lack of access to accurate, update to date, and relevant information. The app will help rural communities to access accurate information, correct and official statistics on COVID-19 cases, and self-assessments based on the individual's symptoms for early detection. The app will help the community access information about COVID-19 in the absence of any other channel for information access by rural communities. Users can access news updates on the pandemic, public health information, fact sheet, preventative information, and outbreak reports. The app provides up-to-date information on the number of active cases, the number of people who have recovered, total deaths, the number of people quarantined or isolated in the country, and a general global outlook. The app will keep rural communities informed on COVID-19 like their urban counterparts and allow them to make the right decisions and choices that impact their health. The app will educate the community to practice the 3-Ws of COVID-19 prevention: Wear, Wait, Wash, as shown in Figure 1.

1) Wear a cloth covering over your nose and mouth.

2) Stand or wait two metres apart; avoid close contact.

3) Wash your hands often with soap and water 

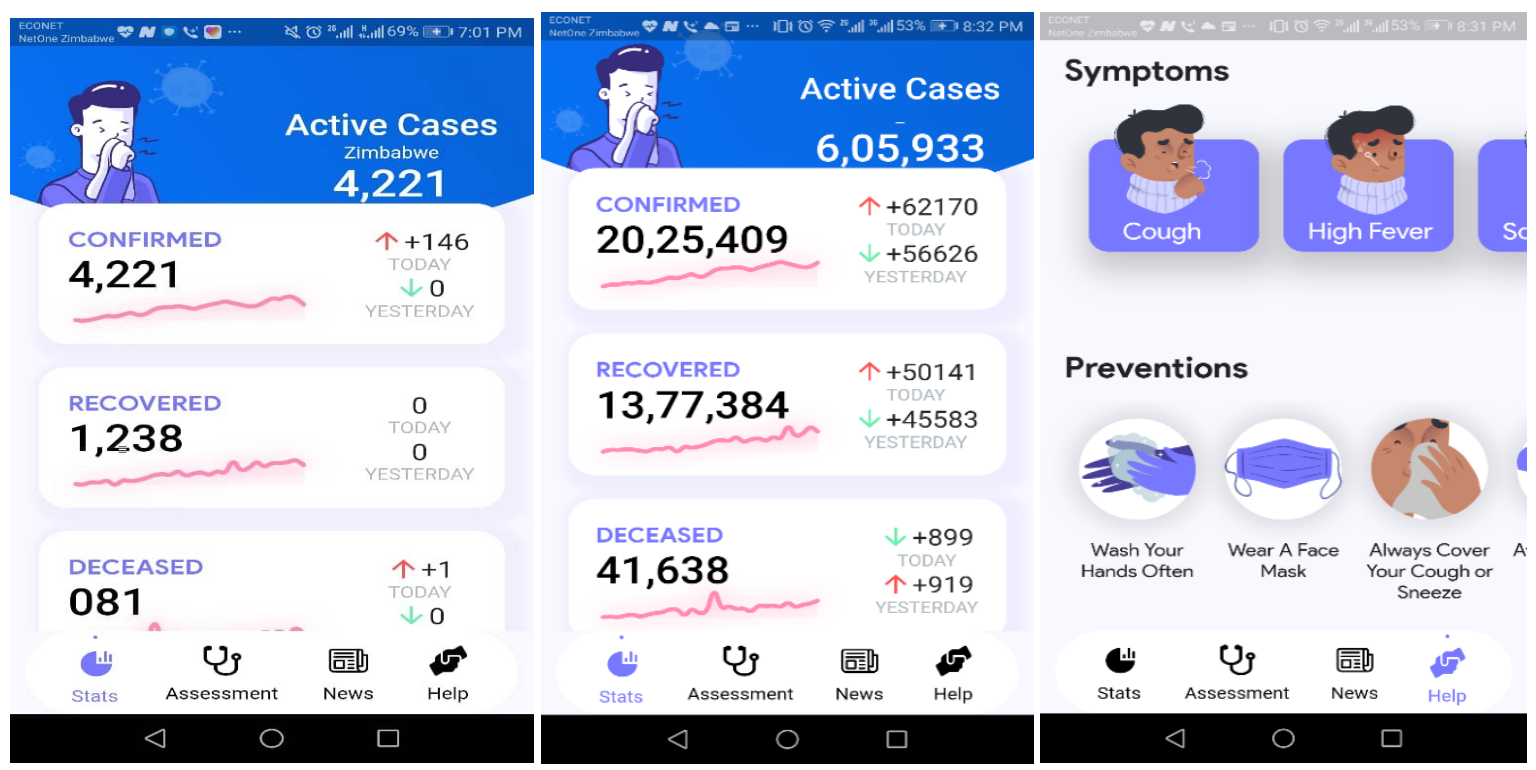

Figure 1. Zimbabwe and global statistics, symptoms, and preventative measures
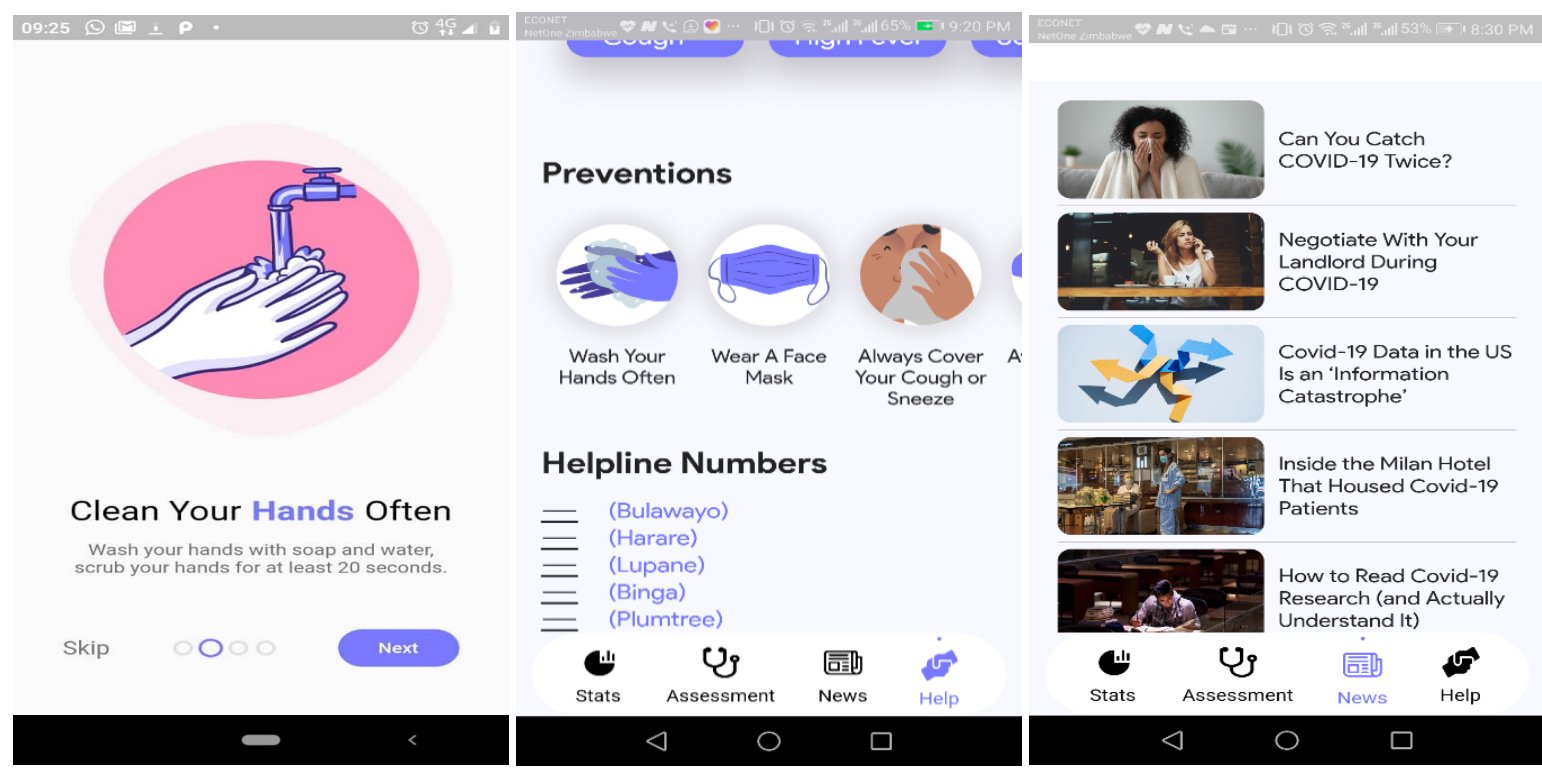

Figure 2. The helpline numbers and news

The app was designed for an Android-based smartphone. The app is linked with the Ministry of Health and Child Welfare and the Centre for Disease Control websites for official national and global statistics. The app offers offline access, allowing the user to input information into the phone's local internal storage. Once connectivity is established, the internally stored data is synchronised with the server. This is a critical feature for apps deployed in low bandwidth environments.

In most rural communities in Zimbabwe, COVID-19 infections are caused by returnees from neighbouring countries such as South Africa and Botswana with higher infection rates. Local communities do not have information on how to handle their returning relatives, who may show such symptoms. The app provides information on what the community can do to unite against COVID-19, such as reporting returnees for screening. It provides basic hygiene information such as the washing of hands, how to sneeze, clean surfaces, and monitoring of symptoms as shown in
Figure 2. The app also provides a list of emergency contact details and a list of referral hospitals and isolation centres for handling COVID-19 cases.

One important innovation of this app is providing users with advice on what to do if they think they have contracted the coronavirus. The app will help the user to understand how they should cope, depending on the severity of the symptoms. In a bid to contain the virus's spread, the app prompts the user to self-evaluate themselves once they suspect to have any of the symptoms based on exposure and travel history, as shown in Figure 3. The app would prompt users if they came into contact with a sick person or someone with COVID-19 during their travel. If the user has a high risk of contracting the virus, the app will guide them on how to isolate and social distance themselves. The app provides advice on whether the user should seek medical help for further assessments or use home remedies and other social distancing measures. Selfevaluation can help detect infections and control the virus's spread in a country whose health system has collapsed. 


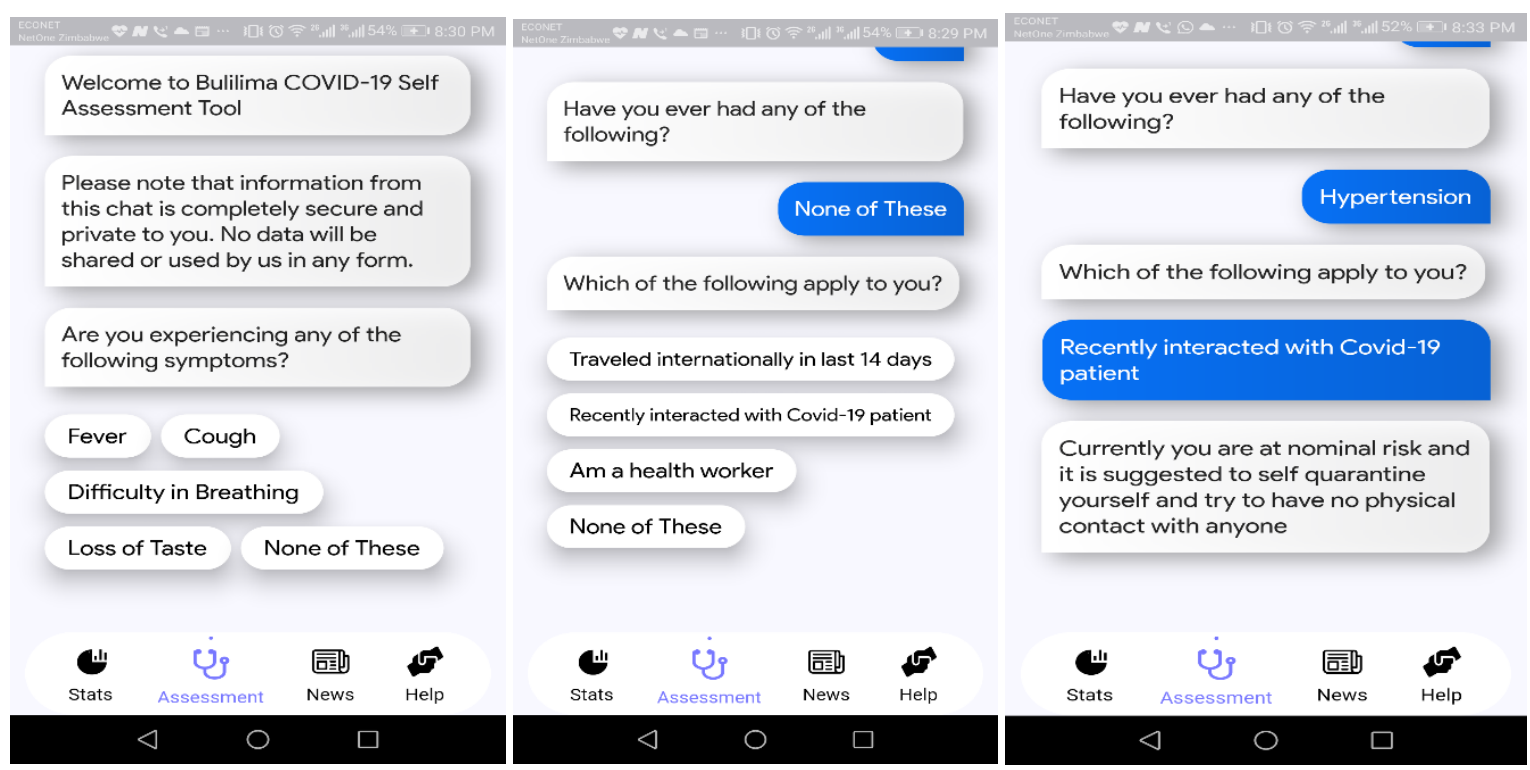

Figure 3. The self-assessment tool and steps

The app will prompt users with the following questions to determine their risk of infection.

1. Which of the following symptoms have you recently experienced? Cough, difficulty breathing, fever, muscle pain, which is not usual?

2. Have you travelled to the city or any country with high infection rates within the past 14 days?

3. Did you come into contact with any person who has travelled to the city or any country with high infection rates within the past 14 days?

4. Did you come into contact with a person who has tested positive for COVID-19 in the past 14 days?

The app also educates the community on COVID-19 symptoms similar to flu and can be mild to severe and often leads to death if no medical attention is sought in time. Some common symptoms include congestion or runny nose, shortness of breath or difficulty in breathing, nausea or vomiting, fatigue, and sore throat (CDC, 2020). The app also provides information on government communication regarding restrictions, curfews and the alert levels that are often announced on radio, television, and newspapers.

\section{EVALUATION}

Usability evaluations were done during a two-month trial period before the app could be deployed to determine if users found it useful, appropriate and pleasant to use. Questions that measured usefulness evaluated how the participants perceived the app to be useful. Results show a mean score of 4.41 and a Cronbach's alpha value of 0.72 , implying that the majority of the participants were satisfied with the app's functionality. The standard deviation value ranged from 0.52 to 0.84 . This is similar to findings by Hussain et al. (2017), who observed that the participants rated the usefulness of a smoking app at $80.25 \%$. Regarding the two questions used to evaluate the app's design, the majority of the participants agreed that the app had good menus and consistent navigation through a mean score of 4.39 while the Cronbach's alpha value was 0.71 . It is essential to design simple solutions for rural communities that are simple to use and do not have a steep learning curve.

One crucial and strong determinant of an app adoption is its learnability, especially when deployed in communities with low digital skills. Four questions were used to evaluate the app's learnability; ease of use, easy to understand, easy to remember, and usage without seeking assistance, as shown in Table 1. An aggregate mean score of 4.56 and a Cronbach's alpha value of 0.79 was observed. The standard deviation value ranged from 0.48 to 0.72 . Learnability findings observed are similar to those established by Khalil et al. (2019), who determined that about $80 \%$ of the participants found that the higher education mobile app was easy to learn. Participants rated their level of satisfaction regarding the appropriateness, relevancy and user-friendliness of the app. Participants were satisfied with the app through an aggregated mean score of 4.35 and a Cronbach's alpha value of 0.82 . A similar study evaluated user satisfaction of a smoking cessation app by Hussain et al. (2017), and they revealed that $79.17 \%$ of the participants agreed that using the app was satisfying.

Mobile apps that have a high degree of memorability are likely to be adopted by users. The app's memorability was evaluated using two questions and had a mean score of 4.51 (90.1\%) and a Cronbach's alpha value of 0.79. The finding is contrary to Khalil et al.'s (2019) observations. They found a lower memorability score of $65 \%$, which indicated that participants had difficulties recalling some of the pages they had visited. Overall, the results show that mobile apps can help rural communities access essential COVID-19 information. The use of mobile apps in developing countries with inadequate health provision can bolster access to health information, helping combat the spread of diseases such as the coronavirus. Otu et al. (2016) observed that there was a $10 \%$ increase in the willingness to practice good hygiene such as hand washing and disinfecting surfaces after the introduction of the Ebola mobile app. The introduction of the app may have positive outcomes related containing the pandemic. 


\section{RECOMMENDATIONS}

There is a need to ensure that rural communities have improved access to information related to COVID-19 to curtail the rapid spread of the virus to disadvantaged communities. The government could partner with mobile network operators to provide zero-rating to selected COVID-19 sites, establish free Wi-Fi hotspots, and expand the mobile network infrastructure. Future designs should ensure that the app captures the user's health status and reports to the district health centre. The app can be improved by establishing twoway communication between the users and the health department by sharing alerts and notifications or other related issues.

\section{CONCLUSION}

Most countries have successfully contained and mitigated the effects of COVID-19 by adopting virtual health care and telemedicine. There is concern that the digital divide will widen as developing countries have limited infrastructure and an underdeveloped health care system. The world is adopting digital technologies to ensure less disruption of daily life and the safety of patients and improve access and the quality of healthcare. The overall conclusion is that developing countries should focus more on improving access to services and health care during the COVID-19 pandemic. Developing countries should embrace mobile health applications as these countries' digital future lie in mobile phone technologies. In light of limited access to radio, television, and newspaper access in rural communities, the study developed and evaluated a mobile app that could enhance access to information related to COVID-19. The evaluation results show overwhelming positive feedback regarding the usefulness and utility of the app. The findings indicate that the participants found the app very easy to remember, easy to learn, and perceived that it satisfied their information access needs. Larger sample sizes would have provided more reliable and generalisable results; it was difficult to establish a larger sample size due to COVID-19 restrictions on movement and gatherings. The results indicate that the application has the potential for widespread deployment in communities with similar socio-economic conditions. The government, health experts, and technologists can use these results to improve digital health solutions targeting rural and remote communities. The results provide a baseline and scope for researchers and practitioners to develop digital solutions for underserved communities.

\section{REFERENCES}

Africaportal. (2020, 14 May). COVID-19: Implications for the 'digital divide' in Africa. Retrieved on 26 July 2020 from https://www.africaportal.org/features/COVID-19-implica tions-of-the-pandemic-for-the-digital-divide-in-africa/

Aker, J., \& Mbiti, I. (2010). Mobile Phones and Economic Development in Africa. Center for Global Development, 144.
Allgaier, J., \& Svalastog, L. (2015). The communication aspects of the Ebola virus disease outbreak in Western Africa - do we need to counter one, two, or many epidemics? Croat Med J, 56(5), 496-499. https://doi.org/10.3325/cmj.2015. 56.496

appsafrica. (2017, 1 March). Sliide Airtime is named Most Innovative Mobile App in world at MWC. Retrieved from Apps: $\quad$ https://www.appsafrica.com/unlockingopportunities-africa-looking-beyond-brexit/

Beuermann, D. W., McKelvey, C., \& Vakis, R. (2012). Mobile Phones and Economic Development in Rural Peru. The Journal of Development Studies, 48(11), 1617-1628. https://doi.org/10.1080/00220388.2012.709615

CDC. (2020, the 13th of May). Symptoms of Coronavirus. Retrieved on 30 July 2020 from https://www.cdc.gov/ coronavirus/2019-ncov/symptoms-testing/symptoms. html?CDC_AA_refVal=https\%3A\%2F\%2Fwww.cdc.gov\%2F coronavirus\%2F2019-ncov\%2Fabout\%2Fsymptoms.html

Chatzipavlou, I., Christoforidou, S., \& Vlachopoulou, M. (2016). A recommended guideline for the development of mHealth Apps. Mhealth, 2, 21-21. https://doi.org/10.21037/ mhealth.2016.05.01

Damasen, I. P., \& Uhomoibhi, J. (2014). Solar electricity generation: issues of development and impact on ICT implementation in Africa. Campus-Wide Information Systems, 31(1), 46-62. https://doi.org/10.1108/CWIS-052013-0018

EWN. (2020, 05 27). Self-screening for COVID-19, there is an app for that. Retrieved from https://ewn.co.za/2020/05/27/ self-screening-for-COVID-19-there-s-an-app-for-that

Hussain, A., Mkpojiogu, E., Abubakar, H., \& Hassan, M. (2017). The usability evaluation of Mudah.my on a mobile device. The 2nd International Conference on Applied Science and Technology 2017 (ICAST'17) (pp. 020058-1-020058-7). AIP Publishing. https://doi.org/10.1063/1.5005391

Iivari, N., Sharma, S., \& Ventä-Olkkonen, L. (2020). Digital transformation of everyday life - How COVID-19 pandemic transformed the basic education of the young generation and why information management research should care? International Journal of Information Management, 1-6. https://doi.org/10.1016/j.ijinfomgt.2020.102183

IPS. (2020, May). COVID-19: The Digital Divide Grows Wider Amid Global Lockdown. Retrieved on 22 July 2020 from http://www.ipsnews.net/2020/05/COVID-19-digitaldivide-grows-wider-amid-global-lockdown/

Khalil, M., Wong, J., Baars, M., Zafar, F., \& Wasson, B. (2019). Evaluating the Usability of a Study Support Mobile App for Higher Education. World Conference on Mobile and Contextual Learning (pp. 85-93).

Lancaster, H. (2016, 25 July). Zimbabwe Telecoms, mobile, and broadband - statistics and analyses. Retrieved from https:// www.budde.com.au/Research/Zimbabwe-TelecomsMobile-and-Broadband-Statistics-and-Analyses

Maphosa, V. (2020). Sustainable Information Access in Rural Communities through Mobile Apps. In K. Schulz, \& K. Minisri (Eds.). Pathways to Connect Creativity and Sustainable Development (pp. 359-384). Nancy: PUN. 
Marinoni, G., van't Land, H., \& Jensen, T. (2020). The impact of COVID-19 on Higher Education around the world. Paris: International Association of Universities (IAU).

Martina, Y. F. (2010). Doing Mixed Methods Research Pragmatically: Implications for the Rediscovery of Pragmatism as a Research Paradigm. Journal of Mixed Methods Research 4(1), 6-16. https://doi.org/10.1177/ 1558689809349691

Matsa, M., \& Simphiwe, M. (2014). Grappling climate change in Southern Zimbabwe: The experience of BaKalanga minority farmers. Sacha Journal of Environmental Studies, 4(1), 34-52.

Meshur, H. F. (2012). Telecenters as an information technology tool for development in urban and rural areas. International Journal of Arts \& Sciences, 5(1), 385-398.

mhealth-hub. (2020, 12 May). Open-coronavirus. Retrieved on 21 July 2020 from https://mhealth-hub.org/opencoronavirus

MoPSE. (2020). Secondary Schools. Retrieved on 20 June 2020 from Ministry of Primary and Secondary Education: http://mopse.co.zw/secondary-school

Neweurope. (2020, 25 June). Is COVID-19 accelerating digitalisation or exposing the digital divide? Retrieved on 15 July 2020 from https://www.neweurope.eu/article/isCOVID-19-accelerating-digitalisation-or-exposing-thedigital-divide/

News Day. (2016, 16 February). Govt violating rural communities' rights: MIHR. Retrieved from https:/www.newsday.co.zw/2016/02/16/govt-violatingrural-communities-rights-mihr/

Nguyen, H. D., \& Poo, D. C. (2016). Analysis and design of mobile health interventions towards informed shared decision making: an activity theory-driven perspective. Journal of Decision Systems, 25(sup1), 397-409. https://doi.org/10.1080/12460125.2016.1187399

Nielsen Norman Group. (2016, the 18th of December). UX Prototypes: Low Fidelity vs High Fidelity. Retrieved from Evidence-Based User Experience Research, Training, and Consulting: https://www.nngroup.com/articles/uxprototype-hi-lo-fidelity/

Otu, A., Ebenso, B., Okuzu, O., \& Osifo-Dawodu, E. (2016). Using a mHealth tutorial application to change knowledge and attitude of frontline health workers to Ebola virus disease in Nigeria: a before-and-after study. Human Resources for Health, 14(5), 1-9. https://doi.org/10.1186/ s12960-016-0100-4

POTRAZ. (2017). Postal and telecommunications sector performance report. Harare: POTRAZ. Retrieved on 11 May 2020 from https://t3n9sm.c2.acecdn.net/wp-content/ uploads/2018/03/Sector-Perfomance-report-4th-Quarter2017-abridged-rev15March2018-1.pdf

Ranscombe, P. (2020). Rural areas at risk during COVID-19 pandemic. thelancet.com/infection, 20, 545. https://doi.org/10.1016/S1473-3099(20)30301-7
Rashid, A. T., \& Elder, L. (2009). Mobile phones and development: An Analysis of IDRC-supported projects. The Electronic Journal of Information Systems in Developing Countries, 36(1), 1-16. https://doi.org/10.1002/j.16814835.2009.tb00249.x

Sezgin, S. (2020). Bridging the Digital Divide Through ODL. In G. Ubachs (Ed.). The Envisioning Report for Empowering Universities (4th ed., pp. 18-20). Netherlands: European Association of Distance Teaching Universities. Retrieved from https://empower.eadtu.eu/images/report/The Envisioning_Report_for_EMPOWERING_Universities_4th_ Edition_2020.pdf

Shambare, R. (2014). The Adoption of WhatsApp: Breaking the Vicious Cycle of Technological Poverty in South Africa. Journal of Economics and Behavioral Studies, 6, 542-550. https://doi.org/10.22610/jebs.v6i7.515

Tech Target. (2013, the 15th of October). Newspaper readership in Zimbabwe continues to decline - ZAMPS 2013. Retrieved from http://www.techzim.co.zw/2013/10/ newspaper-readership-in-zimbabwe-continues-todecline/\#.V-0iQf19601

Tran, X. B., \& Houston, S. (2012). Mobile Phone-Based Antiretroviral Adherence Support in Vietnam: Feasibility, Patient's Preference, and Willingness-to-Pay. AIDS Behav, 16(7), 1988-1992. https://doi.org/10.1007/s10461-0120271-5

TRTWorld. (2020, 15 June). COVID-19 reveals digital divide as Africa struggles with distance learning. Retrieved from https://www.trtworld.com/magazine/COVID-19-revealsdigital-divide-as-africa-struggles-with-distance-learning37299

Tugnayat, R. M., Regulwar, G. B., \& Tugnayat, A. R. (2012). Information and Communication Technologies for rural areas. Information Science and Technology, 2(1), 24-27.

Venkataraman, V. (2020). Switzerland Launches App to Alert People Of COVID Exposure. Retrieved on 29 July 2020 from https://curlytales.com/switzerland-launches-app-toalert-people-of-COVID-exposure/

Wang, C., Horby, P., Hayden, F., \& Gao, G. (2020). A novel coronavirus outbreak of global health concern. Lancet, 395(10223), 470-473. https://doi.org/10.1016/S01406736(20)30185-9

Wayi, N., \& Huisman, M. (2010). A System Development Methodology Framework for Development of Rural Community Based Information Systems in South Africa. International Development Informatics (pp. 1-16). Capetown.

Whitelaw, S., Mamas, A., Topol, E., \& Van Spall, H. (2020). Applications of digital technology in COVID-19 pandemic planning and response. Viewpoint, 2, e334-e340. https://doi.org/10.1016/S2589-7500(20)30142-4

Wijesooriya, R., Mishra, V., Brand, P., \& Rubin, K. (2020). COVID-19 and telehealth, education, and research adaptations. Paediatric Respiratory Reviews, 35, 38-42. https://doi.org/10.1016/j.prrv.2020.06.009

Worldometers. (2020, 25 July). Coronavirus. Retrieved from https://www.worldometers.info/coronavirus/ 
Zimstats. (2014). Information and Communication Technology (ICT) Household Survey 2014. Harare: Zimstats. Retrieved from http://www.zimstat.co.zw/wp-content/uploads/ publications/Economic/Ict/ICT-Report-2014.pdf 